\title{
Limiting Excess Weight Gain in Healthy Pregnant Women: Importance of Energy Intakes, Physical Activity, and Adherence to Gestational Weight Gain Guidelines
}

\author{
Tamara R. Cohen and Kristine G. Koski \\ School of Dietetics and Human Nutrition, Macdonald Campus, McGill University, 21,111 Lakeshore Road, Ste-Anne-de-Bellevue, \\ QC, Canada H9X 3V9
}

Correspondence should be addressed to Kristine G. Koski; kristine.koski@mcgill.ca

Received 13 November 2012; Accepted 16 January 2013

Academic Editor: Riitta Luoto

Copyright (C) 2013 T. R. Cohen and K. G. Koski. This is an open access article distributed under the Creative Commons Attribution License, which permits unrestricted use, distribution, and reproduction in any medium, provided the original work is properly cited.

\begin{abstract}
Few studies have investigated if compliance with energy intakes, physical activity, and weight gain guidelines attenuate postpartum weight retention (PPWR) in mothers attending prenatal classes. We investigated whether (a) daily energy intakes within $300 \mathrm{kcal}$ of estimated energy requirements (EERs), (b) walking more than 5000 steps/day, (c) targeting the recommended weight gain goals for prepregnancy BMI, and/or (d) achieving weekly or total gestational weight gain (GWG) recommendations minimized PPWR in 54 women attending prenatal classes in Montreal/Ottawa, Canada. Participants completed a validated pregnancy physical activity questionnaire (PPAQ), 3 telephone-validated $24-\mathrm{hr}$ dietary recalls, and wore a pedometer for one week. PPWR was measured 6 weeks after delivery. Results showed that $72 \%$ had healthy prepregnancy BMIs. However, $52 \%$ consumed $>300 \mathrm{kcal} / \mathrm{day}$ in excess of their EER, 54\% exceeded recommended GWG, and more overweight (93\%) than normal weight women (38\%) cited nonrecommended GWG targets. Following delivery, 33\% were classified as overweight, and 17\% were obese. Multiple logistic regressions revealed that women targeting "recommended weight gain advice" were 3 times more likely to meet total GWG recommendations (OR: 3.2, $P<0.05$ ); women who complied with weekly GWG goals minimized PPWR (OR: $4.2, P<0.02)$. In conclusion, appropriate GWG targets, lower energy intakes, and physical activity should be emphasized in prenatal education programs.
\end{abstract}

\section{Introduction}

Research describes increasing rates of obesity in women of childbearing age $[1,2]$. With more than $40 \%$ gaining in excess of Institute of Medicine recommendations [1], pregnancy is now emerging as an important risk factor for excessive weight gain [3] and an important target for obesity prevention studies [4]. Although most studies have focussed on multiethnic, socioeconomically disadvantaged obese women $[1,5-$ 7], there is a growing concern that many healthy, universityeducated, nonobese women may also gain excess weight during pregnancy, leading to postpartum weight retention (PPWR) and obesity later in life $[3,8]$. In Canada, national statistics from the Maternity Experiences Study show that primiparous, university-educated women with medium- to high-household incomes gain more than is recommended when compared against recommendations released in 1999 $[9,10]$ or the newer revised 2010 guidelines $[11,12]$, with nearly $50 \%$ exceeding gestational weight gain (GWG) guidelines. The Canadian GWG guidelines [12] were harmonized with the US guidelines $[13,14]$ in 2010.

Despite the existence of GWG guidelines since the 1990's $[10,15]$, recent studies show that most women either receive no GWG advice [16-22] or target nonrecommended GWG goals $[18,23,24]$. Moreover, women no longer cite health professionals as their main source of information but identify the internet and family and friends as main sources of information [6, 24-27].

Because targeted goals [28], dietary and exercise interventions [29], and physical activity (PA) levels [30] have been associated with limiting excessive GWG, our objectives were (1) to investigate in healthy nonobese women 
attending prenatal classes in Ottawa/Montreal, Canada, if Health Canada's GWG targets [12] were being followed by our college-educated prenatal class attendees and (2) to identify specific behaviours that might be associated with achieving current Health Canada's GWG recommendations and/or minimizing postpartum weight retention (PPWR). We investigated the likelihood of achieving a healthy GWG and/or minimizing PPWR for the following four behaviours: (a) daily energy intakes within $300 \mathrm{kcal}$ of estimated energy requirements (EERs); (b) walking more than 5000 steps/day; (c) targeting Health Canada's recommended GWG goals based on the mother's prepregnancy body mass index (BMI); and (d) achieving weekly or total GWG recommendations established by Health Canada [12] for healthy nonobese mothers.

\section{Methods}

2.1. Recruitment. From 18 prenatal classes held in either Ottawa, Ontario, or Montreal, Quebec, between August and December 2008, 142 women were approached in their second and third trimesters to participate in this study. Ethics approvals were obtained from McGill University, Ottawa Public Health Ethics Board, and Centre de Santé de Services Sociaux (CSSS) Montreal (West Island and Cavendish boards). Researchers who were trained clinical nutritionists briefly described the study elements in a fiveminute presentation at the beginning of each prenatal class, and interested clients provided their contact information at the end of class. In Canada, prenatal classes are voluntary and encouraged for first-time parents to learn about all aspects of pregnancy, delivery, and how to care for your newborn. These sessions are offered in both English and French and are free of charge.

Signed consent was obtained for 81 mothers; 54 mothers completed all phases of the study that included a "GWG advice" questionnaire, 3 24-hr dietary recalls obtained by phone on nonconsecutive days, and wearing a pedometer for 7 consecutive days during the same week in which the dietary records were completed; 27 were excluded because they did not complete 3 dietary recalls or wear the pedometer for 7 consecutive days. Final inclusion criteria were for women $>12$ weeks of pregnancy, free of medical risks for PA, as described in the Physical Activity Readiness Medical Examination for Pregnancy (PARmed-X for Pregnancy) [31], and women who were not underweight (prepregnancy BMI $<18 \mathrm{~kg} / \mathrm{m}^{2}$ ) or obese (prepregnancy BMI $>30 \mathrm{~kg} / \mathrm{m}^{2}$ ) and did not have a multiple pregnancy, which is a contraindication as per the PARmed-X.

2.2. Provider Advice Questionnaire. During the first visit, women were interviewed by the principle researcher, a licensed dietitian, on sources of GWG advice. Categories included physician and/or other health professionals, family and friends, and internet or books. The amount of weight each pregnant women was advised to gain was also recorded. Responses were categorized into the following weight ranges: $<6.8 \mathrm{~kg}, 9.1-10.9 \mathrm{~kg}, 11.3-13.1 \mathrm{~kg}, 13.6-15.9 \mathrm{~kg},>15.9 \mathrm{~kg}$, or "no one discussed weight gain with me." Responses reported as ranges (e.g., between 11.3 and $15.9 \mathrm{~kg}$ ) were recorded as the mean of a weight range category. The "recommended advice" was calculated using each women's individual prepregnancy BMI and was compared to the following Health Canada and Institute of Medicine recommendations: BMI < 18.5: 12.5$18 \mathrm{~kg} ; \mathrm{BMI}=18.5-24.9: 11.5-16 \mathrm{~kg} ; \mathrm{BMI}=25.0-29.9: 7-11.5 \mathrm{~kg}$; $\mathrm{BMI} \geq 30: 5-9 \mathrm{~kg}[12,13]$.

2.3. Weight Assessment. Self-reported pre-pregnancy weight and height were obtained at the first home visit as previously described [24]; actual body weight using a Tanita scale was also measured at the first home visit. Weekly GWG was calculated using current pregnancy weight minus prepregnancy weight $(\mathrm{kg})$ divided by week of gestation minus twelve, as previously reported [24]. Self-reported pre-pregnancy weight was defined as weight at conception, and gestational age was based on date of last menstruation. Women were also telephoned at delivery and 6-week postpartum and were asked to report both their measured weight recorded by the physician at the time of delivery and their 6-wk postpartum weight recorded at this routine doctor's visit. This 6-wk time point has also been previously used to represent the maximal fat mass gained during pregnancy [32-34]. Specifically, this 6-wk postpartum measurement is considered a valid early indicator of adipose tissue accumulation during pregnancy because, at this time point, maternal weight is no longer influenced by changes in blood volume arising from pregnancy and/or planned weight loss. PPWR was calculated based on the difference between this 6-wk postpartum weight and the women's self-reported pre-pregnancy weight.

2.4. Physical Activity and Dietary Intake. During a home visit, mothers were instructed on how to wear the pedometer by a certified sports nutritionist. PA was assessed using a New Lifestyles Digi-Walker SW-200 [Step Into Health, Plainfield, $I L, U S A]$ pedometer for one week. Women also completed a PA logbook that included wear time, total steps/day and total time bathing, swimming or napping times, and how these compared with pedometer values. Values were compared to public health recommendations where less than 5000 steps/day is classified as a sedentary lifestyle [35].

Women also completed 3 nonconsecutive telephone dietary recalls during the week they wore the pedometer. Dietary interview kits and training were provided to assist women with estimating food portion sizes during the telephone recalls. The Canadian Nutrient File 2007 [36] and ESHA Research Food Processor (version 9.1) (Salem, OR, USA) were used to analyze food recalls for total energy (kcals) [37]. These were compared to the estimated energy requirements (EERs) (kcal/day) [37]. EER were calculated using the formula from the Dietary Reference Intake which estimates the EER based on age, PA level, height, weight, and the additional requirement associated with pregnancy. For all energy calculations, weights measured during the first home visit were used as previously described [24]. In Canada, in contrast to USA, no increased energy intakes are recommended for the first trimester, but an additional 
TABLE 1: Population characteristics $(n=54)$.

\begin{tabular}{|c|c|}
\hline Characteristic & $($ mean $(\mathrm{SD}))$ \\
\hline Age (y) & $32.0 \pm 4.3$ \\
\hline Height (m) & $1.7 \pm 0.1$ \\
\hline Gestational age (weeks) & $26.8 \pm 6.3$ \\
\hline \multicolumn{2}{|l|}{ Pregnancy weight assessments } \\
\hline Prepregnancy body mass index $\left(\mathrm{kg} / \mathrm{m}^{2}\right)^{\mathrm{a}}$ & $23 \pm 3$ \\
\hline Estimated energy requirements $(\mathrm{kcal} / \mathrm{day})^{\mathrm{b}}$ & $2341 \pm 151$ \\
\hline Average steps per day $(\text { steps/day })^{c}$ & $6133 \pm 2203$ \\
\hline Average energy expenditure (MET-hrs/day) ${ }^{d}$ & $6.6 \pm 2.6$ \\
\hline Total gestational weight gain $(\mathrm{kg})$ & $17.1 \pm 6.4$ \\
\hline Weekly gestational weight gain (kg) & $0.71 \pm 0.44$ \\
\hline \multicolumn{2}{|l|}{ Postpartum weight assessments } \\
\hline Weight retention at 6-wk postpartum $(\mathrm{kg})^{\mathrm{e}}$ & $10.9 \pm 4.5$ \\
\hline Postpartum body mass index $\left(\mathrm{kg} / \mathrm{m}^{2}\right)$ & $25 \pm 4$ \\
\hline \multicolumn{2}{|l|}{${ }^{\mathrm{a}}$ Based on self-reported weight. } \\
\hline \multicolumn{2}{|c|}{$\begin{array}{l}{ }^{\mathrm{b}} \text { Calculated using self-reported prepregnancy weight, self-reported height, } \\
\text { age, and physical activity level. } \\
{ }^{c} \text { Steps per day determined by 7-day wear time of pedometer. } \\
{ }^{\mathrm{d}} \text { MET-hrs/day determined by the pregnancy physical activity questionnaire } \\
\text { [24]. } \\
\text { e }{ }^{\mathrm{e}} \text { Weight retention at 6-wk postpartum was determined by subtracting self- } \\
\text { reported pre-pregnancy weight from the 6-wk value measured at the time of } \\
\text { their routine 6-wk postpartum doctor's visit. }\end{array}$} \\
\hline
\end{tabular}

$340 \mathrm{kcal}$ is recommended for second trimester and an additional $450 \mathrm{kcal}$ for the third trimester [10,12]; these later two values were added to the following equation: $\mathrm{EER}=354-$ $(6.91 \times$ age $[\mathrm{y}])+\mathrm{PA} \times\{(9.36 \times$ weight $[\mathrm{kg}])+(726 \times$ height $[\mathrm{m}])\}[38]$.

2.5. Statistical Analyses. Data was analyzed using Statistical Analysis Software [Version 9.2, 2002-2003, SAS Institute Inc, Cary, NC, USA]. Univariate logistic regressions were used to compute odds ratios (OR) for (a) achieving recommended total GWG and (b) carrying less than $4.5 \mathrm{~kg}$ (10 lbs) of additional weight 6-week postpartum for each of our 4 behaviors. Statistical significance was $P<0.05$.

\section{Results}

3.1. Population Characteristics. Table 1 describes our population characteristics. Participants were mostly Caucasian (85\%), nulliparous (79\%), and married (72\%) women, with college $(74 \%)$ or university degrees $(26 \%)$ and household incomes $>\$ 50,000(82 \%)$ who maintained "low active" lifestyles (6120 \pm 2185 steps/day, range 840-11090 steps/day). Postpartum assessment revealed that the majority delivered healthy infants at term $(39.3 \pm 1.5$ weeks $)(3450 \pm 494 \mathrm{~g})$ either by vaginal delivery (68\%) or planned caesarean section (32\%). Energy intakes ranged from $1080 \mathrm{~kg}$ to $3760 \mathrm{kcal} /$ day (mean $2240 \pm 448$ ); $54 \%$ exceeded their EER, individualized for their trimester, by more than $300 \mathrm{kcal}$ per day. Total GWG ranged from $7.5 \mathrm{~kg}-35 \mathrm{~kg}$ (mean $17.3 \mathrm{~kg}$ ). By 6 weeks postpartum, the majority of women with a pre-pregnancy BMI

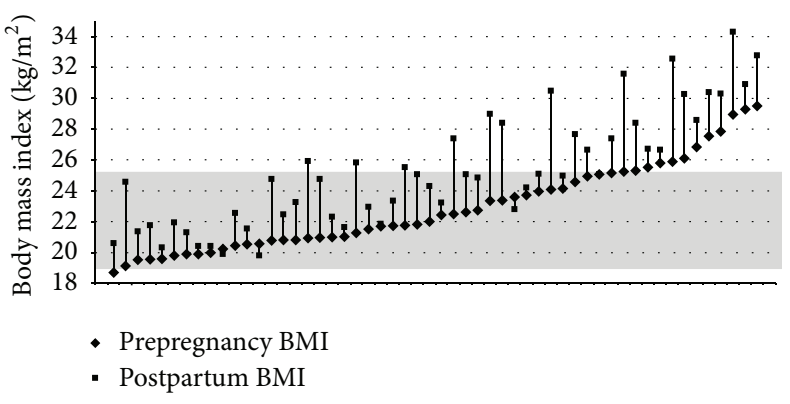

Figure 1: Comparison of Individual Mother's Pre-Pregnancy with their Post-Partum BMI. The differences in the individual weight gains for our 54 mothers are described. The shaded box represents the normal BMI category $\left(18.8-24.9 \mathrm{~kg} / \mathrm{m}^{2}\right)$.

$<25 \mathrm{~kg} / \mathrm{m}^{2}$ (54\%) had retained $>4.5 \mathrm{~kg}$ (mean $5.9 \pm 4.9 \mathrm{~kg}$ ), whereas $60 \%$ of overweight women (pre-pregnancy BMI = $25.0-29.9 \mathrm{~kg} / \mathrm{m}^{2}$ ) had retained $>4.5 \mathrm{~kg}$ (mean $8.2 \pm 6.0 \mathrm{~kg}$ ). Thus, although $72 \%$ began pregnancy having a normal prepregnancy BMI, based on their 6-week postpartum weight, $50 \%$ of study mothers were now classified as overweight or obese $(P>0.001)$ (Figure 1$)$.

3.2. Information Sources. The majority (76\%) received advice about GWG: $49 \%$ from books/internet, $29 \%$ from physicians, $10 \%$ from other health care professionals (dietitian, nurse, and midwife), and $10 \%$ referenced all 3 sources. Twenty four percent of all study participants reported receiving no GWG advice. None cited their prenatal course as a source for their targeted GWG. Those who received practitioner advice or obtained information from books or the internet most often cited $13.6-15.9 \mathrm{~kg}$ as their targeted normal healthy GWG regardless of prepregnancy BMI.

3.3. Adherence to "Recommended" GWG Targets. The majority (61\%) of study participants followed incorrect GWG advice for their prepregnancy BMI. As well, 52\% exceeded recommended weekly rates of GWG, normal prepregnancy BMI averaged $0.6 \pm 0.2 \mathrm{~kg} /$ week; overweight pre-pregnancy BMI averaged $0.7 \pm 0.3 \mathrm{~kg} /$ week. However, univariate logistic regressions showed that women who followed the correct total weight gain for their prepregnancy BMI were three times more likely to achieve Health Canada's GWG recommendations (OR: 3.2, $P<0.05$ ) (Table 2). Women who achieved their recommended weekly rate of GWG were four times more likely to have retained less than $4.5 \mathrm{~kg}$ at 6 week postpartum (OR: 4.2, $P<0.02$ ) (Table 2). Finally, women with a pre-pregnancy BMI $<25 \mathrm{~kg} / \mathrm{m}^{2}$ were nine times more likely to target and to achieve Health Canada recommendations for GWG of 11.5-16 kg (Table 2).

\section{Discussion}

Pregnancy is now considered obesogenic [3], but preventing excessive weight gain is proving to be a challenge [28-30]. In our study, we explored compliance with 3 measurable 
TABLE 2: Odds ratios identifying behaviours associated with achieving a healthy GWG and minimizing PPWR in pregnant women $(n=54)$ attending prenatal classes.

\begin{tabular}{|c|c|c|c|}
\hline & Odds ratio & 95\% Confidence interval & $P$ value \\
\hline \multicolumn{4}{|c|}{ Behaviours associated with achieving an appropriate total gestational weight gain (GWG) } \\
\hline Normal prepregnancy BMI $\left(18.5-24.9 \mathrm{~kg} / \mathrm{m}^{2}\right)$ & 9.6 & $1.88-48.99$ & 0.0065 \\
\hline Consuming within $300 \mathrm{kcal} /$ day of EER & 1.1 & $0.36-3.16$ & 0.9005 \\
\hline Walking $>5,000$ steps/day & 1.4 & $0.35-3.78$ & 0.8271 \\
\hline Following "correct" total weight gain guidelines & 3.2 & $1.04-9.85$ & 0.0426 \\
\hline \multicolumn{4}{|c|}{ Behaviours associated with achieving $<4.5 \mathrm{~kg}$ (10 lbs) postpartum weight retention (PPWR) } \\
\hline Normal pre-pregnancy BMI $\left(18.5-24.9 \mathrm{~kg} / \mathrm{m}^{2}\right)$ & 1.3 & $0.38-4.31$ & 0.6839 \\
\hline Consuming within $300 \mathrm{kcal} /$ day of EER & 1.3 & $0.45-3.84$ & 0.6257 \\
\hline Walking $>5,000$ steps/day & 1.1 & $0.34-3.74$ & 0.8385 \\
\hline Following "correct" total weight gain guidelines & 1.3 & $0.45-3.84$ & 0.6257 \\
\hline Achieving Health Canada's recommended average weekly GWG rate (kg/week) & 4.2 & $1.33-13.27$ & 0.0147 \\
\hline
\end{tabular}

behavioural objectives and their impact on GWG and PPWR in women attending prenatal classes. GWG exceeded Health Canada recommendations in $52 \%$ of our study population, which is similar to other Canadian studies [9, 11, 39]. Our results showed that meeting GWG targets were associated with the following modifiable conditions and behaviours. First, a normal weight BMI $<25 \mathrm{~kg} / \mathrm{m}^{2}$ increased the likelihood of mothers complying with Health Canada GWG guidelines, but a normal prepregnancy BMI did not prevent excessive PPWR, suggesting that behaviours associated with GWG and PPWR were not related to one another, which has been suggested [33]; secondly in both situations-for example, achieving an appropriate GWG or avoiding PPWRneither energy intakes within $300 \mathrm{kcal}$ of a mother's EER or becoming active and walking more than 5000 steps per day directly increased the likelihood of mothers achieving GWG recommendations or avoiding PPWR. Previous research has shown that purposeful walking, as measured by pedometer steps per day is related to weekly rate of GWG $[24,40]$, whereas higher energy intakes predict PPWR [33]. Thirdly our evidence strongly points to the important role for understanding and targeting recommended GWG guidelines and the importance of health care professionals conveying the message. It is well established that provider advice strongly impacts what expectant mothers actually gain $[16,22]$. Should no advice or inappropriate weight gain advice be followed, previous studies show that women will exceed their GWG recommendations $[9,16,22,24]$. Only $61 \%$ followed GWG guidelines for their prepregnancy BMI established by Health Canada. Others have reported lower rates [9, 11, 39].

Our GWG results were greater than a recent Australian study that reported that only $30 \%$ of normal weight women exceeded Institute of Medicine recommendations [41]. Similarly, recent Canadian studies identified $47 \%$ of primiparous mothers and $43 \%$ and $38 \%$ of college- and universityeducated women, respectively, had excessive GWG; there were no differences for mothers from low (43\%) versus high (41\%) household incomes [9]. A second study reported nearly $50 \%$ exceeded GWG, but they found an association with income, ethnicity, and health status of the mother [11]. Taken together, these studies show that pregnant women attending prenatal classes who are not advised to meet GWG recommendations are at an increased risk of exceeding weight gain recommendations and of retaining in excess of $4.5 \mathrm{~kg}$ postpartum if they are sedentary throughout pregnancy as our study did.

Strengths of our study include the fact that we measured energy intakes using 324 -hr recalls and PA by both pedometers and a validated PPAQ [24]. Our previous modeling paper had identified interrelated causal pathways among energy intakes and PA and pregnancy outcomes that were not supported by direct relationships [33]. It is possible that increased PA and lower energy intakes were not associated with GWG and PPWR, which might be explained by the sedentary behavior of our mothers coupled with their high energy intakes. As well, pedometers are considered an acceptable method of assessing PA in pregnant women [42], their sensitivity to tilt angle may be more pronounced as pregnancy progresses and could affect recording of steps [43], thus underestimating PA.

Despite our small sample size, we believe our findings emphasize an important role for prenatal classes to educate pregnant women. Development of a public health promotion strategy for women attending prenatal classes should emphasize correct GWG based on the mother's prepregnancy BMI, appropriate energy intakes, and a nonsedentary lifestyle. In this study, university-educated women who received and followed the correct weight advice were more likely to avoid excessive GWG, and those who complied with weekly GWG which was achieved through "walking" [40], minimized PPWR, but none described their prenatal classes as having these objectives. This study demonstrates that by providing correct GWG targets in prenatal classes early in pregnancy more women can more easily achieve the Health Canada and Institute of Medicine recommendations for GWG and avoid PPWR.

\section{References}

[1] E. M. Davis, K. C. Stange, and R. I. Horowitz, "Childbearing, stress and obesity disparities in women: a public health perspective," Maternal and Child Health Journal, vol. 16, pp. 109-118, 2012. 
[2] J. Yeh and J. A. Shelton, "Increasing prepregnancy body mass index: analysis of trends and contributing variables," American Journal of Obstetrics and Gynecology, vol. 193, no. 6, pp. 19941998, 2005.

[3] K. Melzer and Y. Schutz, "Pre-pregnancy and pregnancy predictors of obesity," International Journal of Obesity, vol. 34, no. 2, pp. S44-S52, 2010.

[4] R. L. Atkinson, A. Pietrobelli, R. Uauy, and I. A. Macdonald, "Are we attacking the wrong targets in the fight against obesity? The importance of intervention in women of childbearing age," International Journal of Obesity, vol. 36, pp. 1259-1260, 2012.

[5] S. J. Herring, D. B. Nelson, A. Davey et al., "Determinants of excessive gestational weight gain in urban, low-income women," Women's Health Issues, vol. 22, no. 5, pp. e439-e446, 2012.

[6] M. R. Stengel, J. L. Kraschnewski, S. W. Hwang et al., "What my doctor didn't tell me: examining health care provider advice to overweight and obese pregnant women on gestational weight gain and physical activity," Women's Health Issues, vol. 22, no. 6, pp. e535-e540, 2012.

[7] A. F. L. Bogaerts, R. Devlieger, E. Nuyts et al., "Effects of lifestyle intervention in obese pregnant women on gestational weight gain and mental health: a randomized controlled trial," International Journal of Obesity, pp. 1-8, 2012.

[8] U. M. S. Koepp, K. Dahl-Jorgensen, H. Stigum et al., "The associations between maternal pre-pregnancy body mass index, gestational weight change during pregnancy and body mass index of the child at 3 years of age," International Journal of Obesity, vol. 36, pp. 1325-1331, 2012.

[9] H. Lowell and D. C. Miller, "Weight gain during pregnancy: adherence to Health Canada's guidelines," Health Reports, vol. 21, no. 2, 2010, Statistics Canada, Component of Statistics Canada Catalogue no 82-003-XPE.

[10] Health Canada, Nutrition for a Healthy Pregnancy: National Guidelines for the Childbearing Years, Minister of Public Works and Government Services Canada, Ottawa, Canada, 1999.

[11] C. Kowal, J. Kuk, and H. Tamim, "Characteristics of weight gain in pregnancy among Canadian women," Maternal and Child Health Journal, pp. 1-9, 2011.

[12] Health Canada, "Canadian gestational weight gain recommendations," http://www.hc-sc.gc.ca/fn-an/nutrition/prenatal/ qa-gest-gros-qr-eng.php, 2010.

[13] Institute of Medicine, "Weight gain during pregnancy: reexamining the guidelines," http://www.iom.edu/Reports/2009/ Weight-Gain-During-Pregnancy-Reexamining-the-Guidelines .aspx, 2009.

[14] A. M. Siega-Riz, A. Deierlein, and A. Stuebe, "Implementation of the new institute of medicine gestational weight gain guidelines," Journal of Midwifery and Women's Health, vol. 55, no. 6, pp. 512-519, 2010.

[15] Institute of Medicine, Nutrition During Pregnancy, National Academies of Sciences Press, Washington, DC, USA, 1990.

[16] M. E. Cogswell, K. S. Scanlon, S. B. Fein, and L. A. Schieve, "Medically advised, mother's personal target, and actual weight gain during pregnancy," Obstetrics and Gynecology, vol. 94, no. 4, pp. 616-622, 1999.

[17] P. Brawarsky, N. E. Stotland, R. A. Jackson et al., "Pre-pregnancy and pregnancy-related factors and the risk of excessive or inadequate gestational weight gain," International Journal of Gynecology and Obstetrics, vol. 91, no. 2, pp. 125-131, 2005.

[18] S. D. McDonald, E. Pullenayegum, V. H. Taylor et al., "Despite 2009 guidelines, few women report being counseled correctly about weight gain during pregnancy," American Journal of Obstetrics and Gynecology, vol. 205, no. 333, pp. e1-e6, 2011.

[19] S. D. McDonald, E. Pullenayegum, K. Bracken et al., "Comparison of midwifery, family medicine, and obstetric patients' understanding of weight gain during pregnancy: a minority of women report correct counseling," Journal of Obstetrics and Gynaecology Canada, vol. 34, no. 2, pp. 129-135, 2012.

[20] N. E. Stotland, P. Gilbert, A. Bogetz, C. C. Harper, B. Abrams, and B. Gerbert, "Preventing excessive weight gain in pregnancy: how do prenatal care providers approach counseling?" Journal of Women's Health, vol. 19, no. 4, pp. 807-814, 2010.

[21] N. Stotland, Y. Teoh, and B. Gerbert, "Prenatal weight gain: who is counseled?” Journal of Women's Health, vol. 21, no. 6, pp. 695701, 2012.

[22] S. Phelan, M. G. Phipps, B. Abrams, F. Darroch, A. Schaffner, and R. R. Wing, "Practitioner advice and gestational weight gain," Journal of Women's Health, vol. 20, no. 4, pp. 585-591, 2011.

[23] S. J. Herring, D. N. Platek, P. Elliott, L. E. Riley, A. M. Stuebe, and E. Oken, "Addressing obesity in pregnancy: what do obstetric providers recommend?" Journal of Women's Health, vol. 19, no. 1, pp. 65-70, 2010.

[24] T. R. Cohen, H. Plourde, and K. G. Koski, "Are Canadian women achieving a fit pregnancy? A pilot study," Canadian Journal of Public Health, vol. 101, no. 1, pp. 87-91, 2010.

[25] J. Huberty, D. Dinkel, M. W. Beets, and J. Coleman, “Describing the use of the internet for health, physical activity, and nutrition inormation in pregnant women," Maternal and Child Health Journal, 2012.

[26] C. Sparud-Lundin, A. Ranerup, and M. Berg, "Internet use, needs and expectations of web-based information and communication in childbearing women with type 1 diabetes," $B M C$ Medical Informatics and Decision Making, vol. 11, pp. 49-55, 2011.

[27] J. A. Herman, K. Mock, D. Blackwell, and T. Hulsey, "Use of a pregnancy support web site by low-income African American women," Journal of Obstetric, Gynecologic, and Neonatal Nursing, vol. 34, no. 6, pp. 713-720, 2005.

[28] M. J. Brown, M. Sinclair, D. Liddle et al., "A systematic review investigating healthy lifestyle interventions incorporating goal setting strategies for preventing excess gestational weight gain," PLOS One, vol. 7, no. 7, Article ID e39503, 2012.

[29] H. Skouteris, L. Hartley-Clark, M. McCabe et al., "Preventing excessive gestational weight gain: a systematic review of interventions," Obesity Reviews, vol. 11, no. 11, pp. 757-768, 2010.

[30] I. Streuling, A. Beyerlein, E. Rosenfeld, H. Hofmann, T. Schulz, and R. Von Kries, "Physical activity and gestational weight gain: a meta-analysis of intervention trials," BJOG, vol. 118, no. 3, pp. 278-284, 2011.

[31] L. A. Wolfe and M. Mottola, "Physical Activity Readiness Medical Examination for Pregnancy [PARmed-X for pregnancy]," Canadian Society for Exercise Physiologists, pp. 1-4, http://uwfitness.uwaterloo.ca/PDF/parmed-xpreg_000.pdf, 2002.

[32] L. O. Walker, B. S. Sterling, and G. M. Timmerman, "Retention of pregnancy-related weight in the early postpartum period: Implications for women's health services," Journal of Obstetric, Gynecologic, and Neonatal Nursing, vol. 34, no. 4, pp. 418-427, 2005.

[33] A. E. Montpetit, H. Plourde, T. R. Cohen, and K. G. Koski, "Modeling the impact of prepregnancy BMI, physical activity, and energy intake on gestational weight gain, infant birth 
weight, and postpartum weight retention," Journal of Physical Activity and Health, vol. 9, pp. 1020-1029, 2012.

[34] A. Sohlstrom and E. Forsum, "Changes in adipose tissue volume and distribution during reproduction in Swedish women as assessed by magnetic resonance imaging," American Journal of Clinical Nutrition, vol. 61, no. 2, pp. 287-295, 1995.

[35] C. Tudor-Locke and D. R. Bassett, "How many steps/day are enough? preliminary pedometer indices for public health," Sports Medicine, vol. 34, no. 1, pp. 1-8, 2004.

[36] Health Canada, "Canadian Nutrient File," http://www.hcsc.gc.ca/fn-an/nutrition/fiche-nutri-data/index-eng.php, 2010.

[37] Institute of Medicine (US) Panel on Macronutrients, Standing Committee on the Scientific Evaluation of Dietary Reference Intakes., Dietary Reference Intakes For Energy, Carbohydrate, Fiber, Fat, Fatty Acids, Cholesterol, Protein, and Amino Acids, vol. xxv, National Academies Press, Washington, DC, USA, 2005.

[38] WHO and FAO, Human Energy Requirements Report of a Joint FAO/WHO/UNU Expert Consultation Food and Agriculture Organization, Food and Nutrition Technical Report Series, Energy Requirements of Pregnancy, Rome, Italy, 2004.

[39] F. Begum, I. Colman, L. J. McCargar, and R. C. Bell, "Gestational weight gain and early postpartum weight retention in a prospective cohort of Alberta women," Journal of Obstetrics and Gynaecology Canada, vol. 34, no. 7, pp. 637-647, 2012.

[40] T. R. Cohen, H. Plourde, and K. G. Koski, "Use of the pregnancy physical activity questionnaire (PPAQ) to identify behaviours associated with appropriate gestational weight gain during pregnancy," Journal of Physical Activity and Health. In press, http://www.ncbi.nlm.nih.gov/pubmed/23132834.

[41] S. J. de Jersey, J. M. Nicholson, L. K. Callaway, and L. A. Daniels, "A prospective study of pregnancy weight gain in Australian women," Australian and New Zealand Journal of Obstetrics and Gynaecology, vol. 52, no. 6, pp. 545-551, 2012.

[42] D. S. Downs, G. C. LeMasurier, and J. M. DiNallo, "Baby steps: pedometer-determined and self-reported leisure-time exercise behaviors of pregnant women," Journal of Physical Activity and Health, vol. 6, no. 1, pp. 63-72, 2009.

[43] C. L. Harrison, R. G. Thompson, H. J. Teede, and C. B. Lombard, "Measuring physical activity during pregnancy," International Journal of Behavioral Nutrition and Physical Activity, vol. 8, no. 19, 2011, http://www.ijbnpa.org/content/8/1/19. 


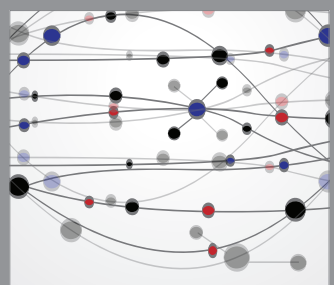

The Scientific World Journal
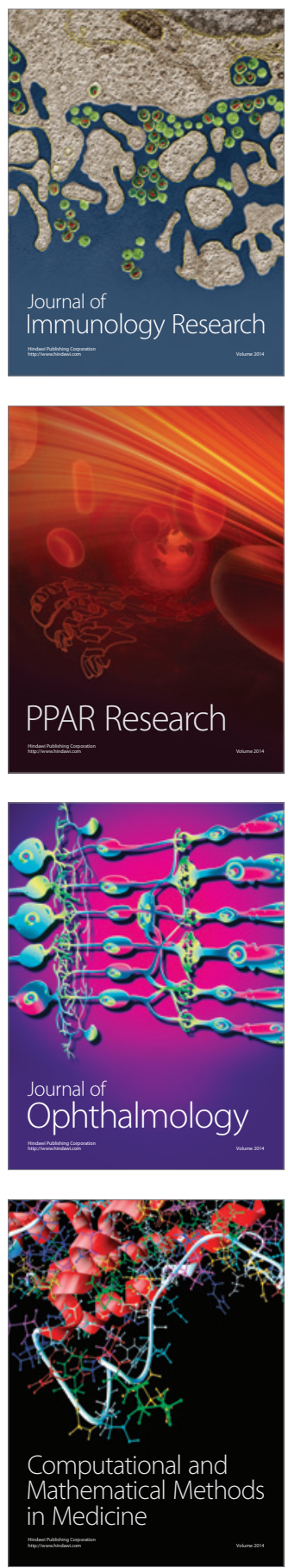

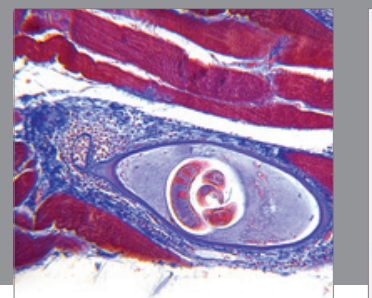

Gastroenterology

Research and Practice
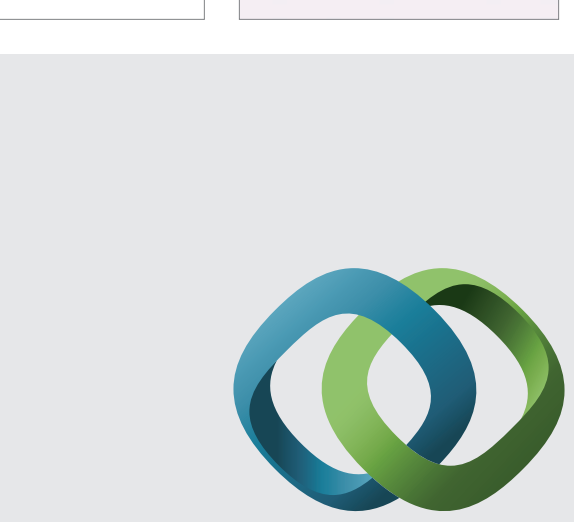

\section{Hindawi}

Submit your manuscripts at

http://www.hindawi.com
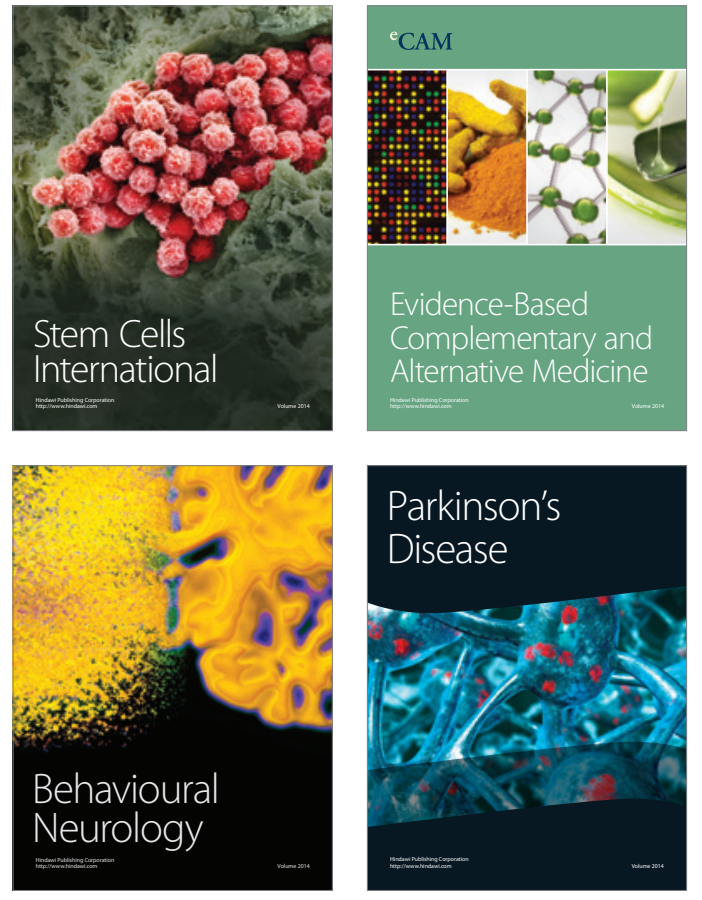
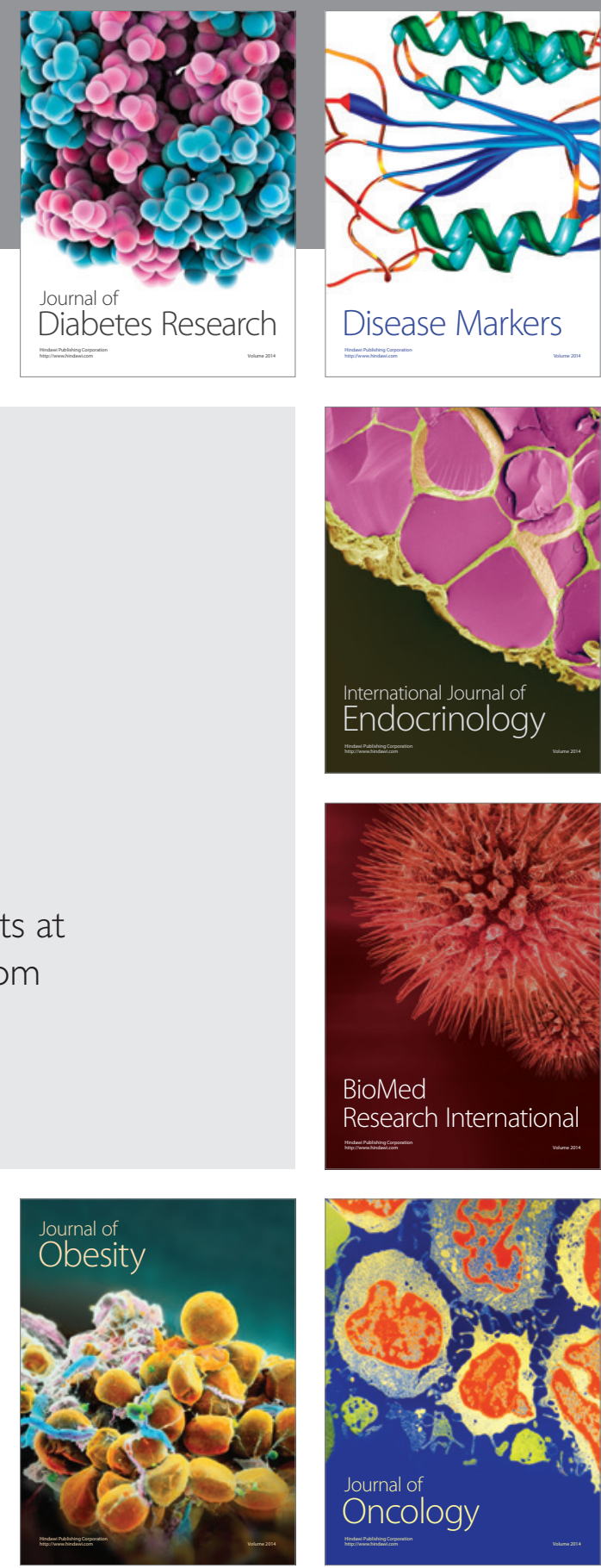

Disease Markers
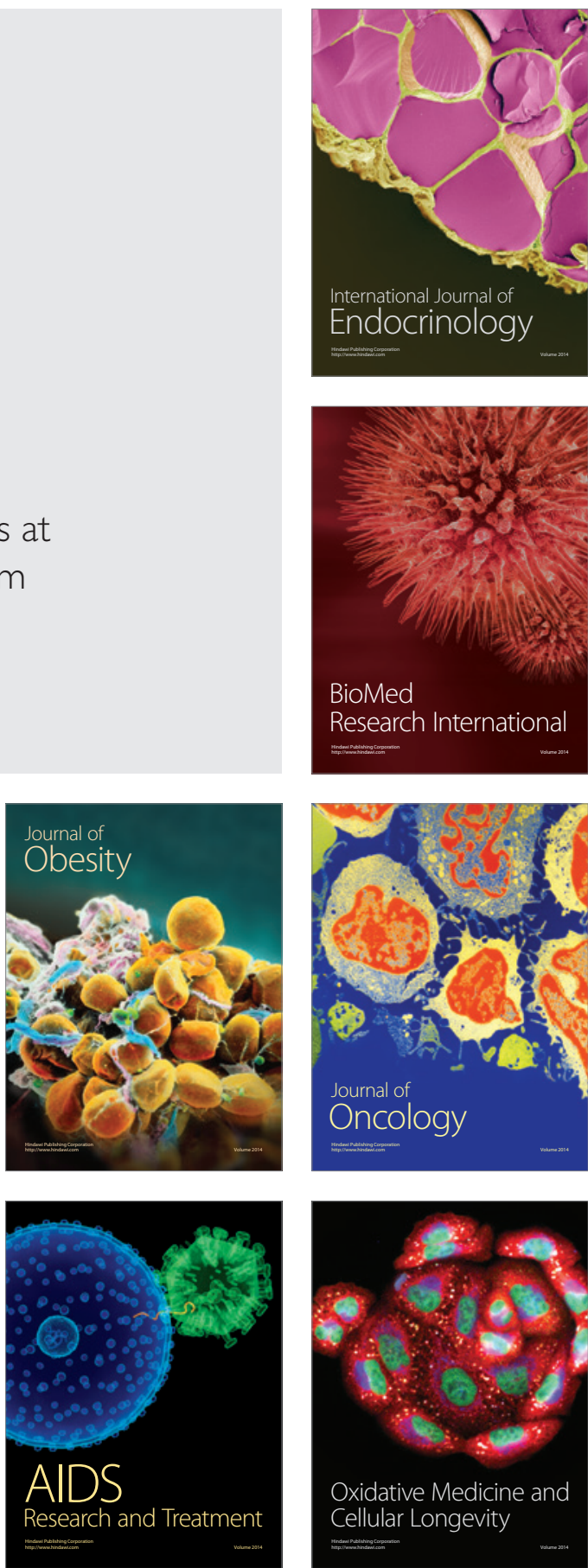